\title{
INTRODUCTION
}

\section{Research in the Frontiers between Biology, Chemistry and Physics}

In this issue of $S R E W$ we offer four reviews describing each of them several years of research work in their respective group in Argentina.

The interaction of light with the biosphere (area of research called photobiology) is of increasing interest in the world and the Argentinian scientists (from the end of the world) have not been absent.

In fact, there is a very active Argentinian Group of Photobiology (called GRAFOB from the name in Spanish, https:// grupoargentinodefotobiologia.info/site/site/grupar/), created in 2011, that has already held five successful meetings in various cities in the country and counts with about 200 members from ca 20 groups in many places in Argentina, some of them with a very long tradition of and internationally appreciated research. Two of the several groups working in Photobiology in Argentina present in this issue an overview of their research.

Mario Guido tells us how research in his laboratory at the National University in Córdoba has provided important contributions to the discovery and understanding of the non-visual photoreceptors in vertebrates. These photoreceptors, present in the inner retina of the animals, furnish them with a broad spectral sensitivity and serve them to regulate several vital functions (non-image forming tasks), even before vision (image formation) occurs.

M. Gabriela Lagorio with her group at the University of Buenos Aires has developed fluorescence detection methods and the necessary models to study and interpret the emission of light by living organisms, i.e., by complete fruits, flowers and plants in general as well as by reptiles. Using these methods, in a real multidisciplinary effort and carrying on sophisticated experiments, performed all in Argentina and Brazil, the first emission from frogs (from Boana punctata, a South-American species) could be analyzed, quantified, and its origin traced back to a novel fluorophore.

The group led by Gabriel Rabinovich has made breakthrough contributions about the role of galectins, a family of soluble lectins as regulators of immune responses. In this issue we offer their authoritative review on the role of Galectin-1driven regulatory circuits for immunity in cancer and autoimmune inflammation. As stated by the authors, understanding the cellular pathways that control Gal-1 expression and function in tumor and inflammatory microenvironments will set the bases for the design of rational therapies based on positive or negative modulation of this endogenous lectin in cancer and autoimmune diseases.

José A. Olabe is well known for his seminal work on the role of coordination chemistry in the modulation of the properties of the bound ligands. In his article he reviews in deep the fascinating chemistry of nitric oxide, a key intermediate in the nitrogen redox cycles that operate in soils, water and human fluids to provide reversible interconversion pathways between nitrate and ammonia.

All in all, the four reviews comprising this issue of Science reviews from the end of the world provide a good insight on the research being carried out in Argentina in the frontiers between biology, chemistry and physics.

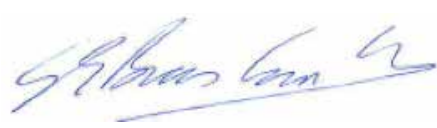

Silvia E. Braslavsky

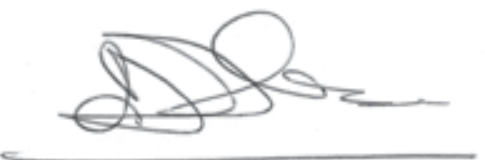

Miguel A. Blesa 


\section{Bio}

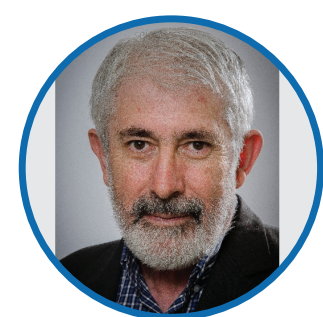

\section{Miguel A. Blesa}

$\mathrm{Ph} \quad \mathrm{D}$ in Chemistry, La Plata University. Formerly: Chemistry Manager (Atomic Energy Commission); Federal Undersecretary of Science and Technology; Senior Researcher (CONICET); Full Professor (San Martín University); President (Argentine
Associaition for the Advancement of Science). Past President, Interciencia Associaition. Member of the National Academy of Science (Córdoba), National Academy of Exact, Natural and Physical Sciences (ANCEFN) and Academy of Sciences of Latin America. TWAS Prize in Chemistry (2004). Konex Merit Diploma in Chemsitry (2003). President for Argentina in the Bilateral French Argentine Cooperation Program (ECOS-SUD). Main research interests: chemistry of metal oxide particles immersed in water; environmental chemistry.

\section{Guest Editor of this Issue}

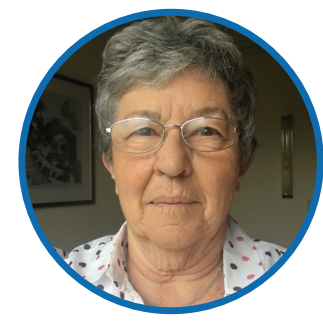

\section{Silvia E. Braslavsky}

Silvia E. Braslavsky is Ph.D. of the Univ. Buenos Aires (UBA, 1968). She was a Professor at the Universidad Nacional de Rio Cuarto (1972-75). From 1976 until her retirement in 2007 she led studies on the molecular properties of biological photoreceptors at the Max-Planck Institute for Radiation Chemistry (today for Chemical
Energy Conversion). She is a corresponding member of CONICET and Dr. honoris causa of the Univ. Ramon Llull (Barcelona) and of UBA, is Honorary (Univ. La Plata) and Distinguished (Univ. Ottawa and Univ. Cordoba) Professor. From 2000 to 2018 she chaired the IUPAC SubCommittee on Photochemistry. She was de scientific chair of the International Congress on Photobiology (Cordoba, 2014), received the Raices Prize (2011, MINCyT, Argentina) and the Finsen medal (2019, International Union on Photobiology). 


\section{IN THIS ISSUE}

\section{Illuminating the Inner retina of Vertebrates: Multiple Opsins and Non-Visual Photoreceptors}

Received: 08/24/2020 - Approved for publication: 11/05/2020

Mario E. Guido

\section{Biophotonics. Fluorescence and Reflectance in Living Organisms}

Received: 08/24/2020 - Approved for publication: 11/05/2020

M. Gabriela Lagorio, Gabriela B. Cordon, Analia Iriel, Juan M. Romero, Julián Faivovich and Carlos Taboada

\section{Recalibrating Immunity in Cancer and Autoimmune Inflammation by Galectin-1-Driven Regulatory}

Received: 09/10/2020 - Approved for publication: 09/22/2020

Camila A. Bach, Anabela M. Cutine, Lorena Laporte, Yamil D. Mahmoud, Montana N. Manselle Cocco, Mora Massaro, Joaquín P. Merlo, Ramiro M. Perrotta, Nicolas Sarbia, Florencia Veigas and Gabriel A. Rabinovich

\section{Coordination Chemistry of Nitric Oxide and Biological Signaling}

Received: 10/03/2020 - Approved for publication: 11/09/2020

José A. Olabe 